\title{
Kearifan Lokal dan Pengembangan Identitas untuk Promosi Wisata Budaya di Kabupaten Banyumas
}

\author{
Triana Ahdiati ${ }^{1}$, Solahuddin Kusumanegara ${ }^{2}$ \\ Affiliation \\ 1,2Jurusan IImu Politik, Universitas Jenderal Soedirman \\ Correspondence
}

Triana Ahdiati. Jurusan IImu Politik Universitas Jenderal Soedirman. Brubahan, Grendeng, Purwokerto Utara, Banyumas, Jawa Tengah, 53122. Email: triana.ahdiati@unsoed.ac.id

\begin{abstract}
The development of local identity reflecting the local wisdom in the tourism development aims at maximizing the local values in developing the area. This research-based paper describes the local wisdom and the development of local identity to promote cultural tourisme in Banyumas. By using a qualitative method and a case study as its approach, the research reveals that the tourism development in the Banyumas regency has not focused on the development of its local identity yet. Cablaka as the local identity of the Banyumas society has not become the way of life. In this case, it has not absorbed into every sector of the Banyumas people' lives, including the tourism sector. The local wisdom in the tourism development is important for a society-including the Banyumas society-to get a better regional income. It means the tourism develoment through implementating the local wisdom is able to improve the life condition of a society better than before. So, the tourism development-especially promoting the cultural tourism-in the Banyumas regency does need to develop the local identity through its local values.
\end{abstract}

Keywords: Local wisdom; Local identity; Cultural tourism; Development.

Article Information

Submitted 21 May 2019 | Revised 13 December 2019 | Accepted 3 September 2020

Recommended Citation: Ahdiati, T., Kumumanegara, S. (2020). Kearifan Lokal dan Pengembangan Identitas untuk Promosi Wisata Budaya di Kabupaten Banyumas. Jurnal Pariwisata Terapan, 4(1), 25-34. https://doi.org/10.22146/jpt.50417 


\section{Pendahuluan}

Para ahli antropologi sering menyebut kebudayaan sebagai blueprint karena hakikat kebudayaan itu sendiri yang menjadi pedoman menyeluruh bagi kehidupan manusia. Seperti yang diungkapkan oleh Parsudi Suparlan: "Kebudayaan sebagai pengetahuan manusia sebagai makhluk sosial, yang isinya ialah perangkat-perangkat model-model pengetahuan, yang secara selektif digunakan oleh para pendukung/ pelakunya untuk mengintepretasi dan memahami lingkungan yang dihadapi, dan digunakan sebagai referensi atau pedoman untuk bertingak (dalam bentuk kelakuan dan benda-benda kebudayaan) sesuai dengan lingkungan yang dihadapi" (Suparlan, 1986: 106).

Kebudayaan menjadi patokan hidup bagi masyarakat sebagai pelakunya. Lebih jauh kebudayaan mencakup keyakinan-keyakinan, norma-norma, nilai-nilai, asumsi-asumsi, pengharapan-pengharapan dan rencana-rencana tindakan yang mewarnai masyarakat pemangku/ pelaku kebudayaan tersebut. Oleh karena itu, kebudayaan itu dipelajari, dibagikan/ disebarluaskan, dan diadaptasi. Kebudayaan pun merupakan sebuah sistem yang dinamis yang dapat berubah secara terus menerus sepanjang masa (Spradley \& Rynkiewich, 1975: 7-8).

Dalam kehidupan nyata, kebudayaan diwujudkan dalam tindakan-tindakan sehari-hari oleh masyarakat setempat sebagai penggunanya. Hal ini hanya mungkin terjadi karena adanya pranata-pranata sosial yang dipunyai oleh masyarakat tersebut. Pranata sosial sendiri merupakan: "sistem antar hubungan peranan-peranan dan norma-norma yang terwujud sebagai tradisi untuk usaha-usaha pemenuhan kebutuhan-kebutuhan sosial utama tertentu, yang dirasakan perlunya oleh para warga masyarakat yang bersangkutan" (Suparlan, 1986: 108).

Sementara itu, sebuah kebudayaan yang dijadikan blueprint oleh masyarakat setempat tidaklah diwariskan secara genetik. Kebudayaan dipahami dan melekat pada manusia sebagai anggota masyarakat suatu daerah setelah kelahirannya melalui proses belajar. Hal itu terjadi karena manusia mempunyai kemampuan untuk membuat dana memahami ideide yang abstrak serta mewujudkan kelakuan simbolik, yang mencerminkan kebudayaan yang digunakannya. Kemampuan manusia dalam mempelajari dan menggunakan kebudayaannya tersebut didasari oleh bahasa yang dimilikinya (Suparlan, 1986: 108).

Selain sebagai alat komunikasi, bahasa juga mencerminkan nilai-nilai budaya yang diyakini oleh masyarakat penggunanya. Nilai-dalam hal ini, nilai budaya-merupakan konsepsikonsepsi yang diinginkan. Artinya, nilai-nilai budaya menjadi asumsi-asumsi yang membentuk setiap aspek dalam kehidupan masyarakat. Karena hakikat nilai budaya merupakan "a total framework which provides an integrated conception of reality" (Spradley \& Rynkiewich, 1975: 361-362), maka nilai budaya itu sendiri pun berfungsi menyatukan manusia sebagai individu-individu dalam sebuah masyarakat. Namun karena hakikat manusia sebagai individu itu sendiri unik, maka selain dapat menyatukan masyarakat, nilai budaya sebagai sektor kebudayaan utama pun dapat menciptakan konflik ketika sektorsektor kebudayaan lain dan masyarakat penggunanya berubah pada tingkat kecepatan yang berbeda. 
Karena nilai budaya merupakan kerangka pemikiran total masyarakat yang meyakininya, yang berarti juga menjadi inti kebudayaan masyarakat penggunanya, maka nilai budaya pun menjadi identitas masyarakat tersebut. Dalam hal ini identitas menjadi ciri yang membedakan masyarakat satu dengan masyarakat lainnya. Ini terjadi karena identitas itu sendiri "socially constructed and culturally defined" (Segal, 1997: 184). Hal ini berarti bahwa identitas merupakan ciri/ karakteristik yang mewakili sebuah masyarakat sebagai kelompok etnis yang berbeda karena kedaerahannya, yang berarti pula menjadi karakteristik lokal suatu masyarakat. "An 'ethnic group' is supposed to be a cultural category, of which there are said to be certain continuing behaviours that are passed on from generation to generation and that are not normally linked in theory to state boundaries" (Wallerstein, 1991: 77).

Bagi masyarakat Banyumas, yang juga sebagai pemilik dan pengguna kebudayaan Banyumas, nilai Budaya yang diyakininya adalah nilai budaya yang mencerminkan karakteristik budaya Banyumasan. Berbeda dengan masyarakat yang tinggal di daerah Jawa Tengah lainnya yang berada di daerah sebelah timur (baik yang melalui arah utara maupun selatan) Banyumas, masyarakat Banyumas memiliki karakteristik yang unik, yang dipengaruhi oleh setting keberadaan masyarakatnya, baik secara geografis maupun historis. Nilai budaya yang menjadi karakteristik utama masyarakat Banyumas adalah nilai blaka suta (keterusterangan). Nilai inilah seharusnya yang menjadi dasar bagi pengembangan pariwisata sebagai bagian dari pembangunan daerah Banyumas.

Sebagai bagian dari pembangunan, pengembangan pariwisata di daerah Banyumas, seperti juga di daerah-daerah lainnya, harus dilakukan secara menyeluruh dan terintegrasi. Ini terjadi karena pariwisata itu sendiri terdefinisi sebagai "the sum of the phenomena and relationships arising from the interaction of tourists, business suppliers, host governments, and host communities in the process of attracting and hosting these tourists and other visitors" (Mclntosh, Goeldner \& Ritchie, 1995: 10). Di sini, terlihat ada 4 (empat) unsur utama sebagai perspektif masing-masing yang berbeda yang mempengaruhi keberhasilan pengembangan pariwisata di sebuah daerah:

1. Wisatawan, yaitu mereka yang mencari pengalaman dan kepuasan fisik dan psikis, yang menetukan tujuan yang dipilih dan aktivitas yang dinikmati.

2. Pengusaha/ wiraswastawan, yaitu mereka yang menyediakan barang-barang dan layanan jasa wisata, yang melihat pariwisata sebagai sebuah kesempatan untuk mendapatkan keuntungan dengan menyediakan barang-barang dan layanan yang diminati pasaran wisata.

3. Pemerintah Daerah, yaitu para politisi yang melihat pariwisata sebagai faktor kemakmuran dalam ekonomi yurisdiksi mereka, di mana perspektif mereka dihubungkan dengan penghasilan warga sekitar yang didapat dari bisnis mereka masing-masing.

4. Masyarakat setempat, yaitu masyarakat lokal yang biasanya melihat pariwisata sebagai faktor budaya dan ketenagakerjaan, yang bisa pula menjadi ajang relasirelasi antara pengunjung mancanegara dengan penduduk sekitar, baik relasi yang mendatangkan keuntungan maupun relasi yang mendatangkan kerugian. 
Di Kabupaten Banyumas, pariwisata belum dikembangkan secara optimal dan masih merupakan sektor yang kurang signifikan dalam mendukung otonomi daerah. Berdasarkan pada data Badan Pusat Statistik (BPS) Tahun 2018, Produk Domestik Regional Bruto (PDRB) Kabupaten Banyumas tahun 2018 adalah sebesar 49,896 trilyun rupiah. Sektor-sektor penyumbang yang besar adalah sebagai berikut: 1) Industri pengolahan (24,34\%); 2) Perdagangan besar dan eceran, reparasi mobil dan sepeda motor (15,28 \%); 3) Konstruksi $(13,25 \%)$; 4) Pertanian, kehutanan dan perikanan (12,37\%) (BPS Kabupaten Banyumas, 2019: 188 \& 190). Secara rinci, gambaran sektor-sektor penyumbang PDRB tergambar dalam Tabel 1.

Tabel 1. PDRB Kabupaten Banyumas Atas Dasar Harga Berlaku Menurut Lapangan Usaha (juta rupiah dan persentasenya) Tahun 2018

\begin{tabular}{lll}
\hline \multicolumn{1}{c}{ Sektor } & \multicolumn{1}{c}{ Jumlah } & \multicolumn{1}{c}{ Persentase } \\
\hline Pertanian, Kehutanan, dan Perikanan & $6.351 .391,20$ & 12,73 \\
\hline Pertambangan dan Penggalian & $2.854 .729,86$ & 5,72 \\
\hline Industri Pengolahan & $12.143 .970,93$ & 24,34 \\
\hline Listrik dan Gas & $47.242,35$ & 0,09 \\
\hline Pengadaan Air, Pengelolaan Sampah, Limbah dan Daur Ulang & $37.158,97$ & 0,07 \\
\hline Konstruksi & $6.613 .480,83$ & 13,25 \\
\hline Perdagangan Besar dan Eceran, Reparasi Mobil dan Sepeda Motor & $7.624 .997,48$ & 15,28 \\
\hline Transportasi dan Pergudangan & $1.743 .295,09$ & 3,49 \\
\hline Penyediaan Akomodasi dan Makan Minum & $1.645 .170,25$ & 3,30 \\
\hline Informasi dan Komunikasi & $2.325 .242,06$ & 4,66 \\
\hline Jasa Keuangan dan Asuransi & $1.609 .030,80$ & 3,22 \\
\hline Real Estate & $1.099 .535,56$ & 2,20 \\
\hline Jasa Perusahaan & $154.803,08$ & 0,31 \\
\hline Administrasi Pemerintahan, Pertahanan dan Jaminan Sosial Wajib & $1.527 .189,02$ & 3,06 \\
\hline Jasa Pendidikan & $2.750 .600,83$ & 5,51 \\
\hline Jasa Kesehatan dan Kegiatan Sosial & $496.947,46$ & 1,00 \\
\hline Jasa lainnya & $871.340,98$ & 1,75 \\
\hline TOTAL & $49.896 .126,75$ & 100,00 \\
\hline
\end{tabular}

(Sumber: BPS Kabupaten Banyumas, 2019: 188 \& 190)

Implementasi pengembangan wisata di Kabupaten Banyumas masih berorientasi pada wisata alam-terutama di Baturraden-yang dipandang memberikan kontribusi besar bagi pendapatan asli daerah (PAD). Sementara itu, muncul keunikan dalam pengembangan wisata budaya. Di satu sisi, wisata budaya masih belum bisa dikembangkan dengan alasan fasilitas dan sarana yang ditampilkan belum mempunyai daya tarik tinggi, namun pada sisi lainnya wisata budaya dianggap sebagai kekuatan pariwisata sehingga perlu untuk dikembangkan. Dengan demikian, ditemukan kontradiksi sikap pemerintah dalam mengembangkan wisata budaya.

Jika upaya pengembangan wisata budaya berarti menggali identitas lokal dan memanfaatkannya untuk kepentingan ekonomi masyarakat maka dapat dikatakan bahwa Pemerintah Kabupaten Banyumas bersikap kontradiktif dalam mengembangkan identitas lokal yang sebenarnya dapat dimanfaatkan untuk mendukung otonomi daerah melalui promosi wisata budaya. Dikaitkan dengan pentingnya pariwisata bagi penguatan otonomi daerah saat ini, maka kiranya cukup urgen untuk mengeksplorasi lebih jauh pengembangan identitas lokal untuk mempromosikan wisata budaya di Kabupaten Banyumas. 


\section{Metode}

Artikel ini ditulis berdasarkan penelitian yang dilakukan dengan metode penelitian kualitatif. Sementara pendekatan yang digunakan adalah studi kasus. Teknik pengumpulan data yang digunakan dalam penelitian ini adalah wawancara mendalam, observasi; dan studi dokumen. Data yang sudah terkumpul dianalisa dengan menggunakan model analisis interaktif dari Miles and Huberman (1992). Untuk mendapatkan kesimpulan yang sahih, maka hasil analisis data divalidasi lagi dengan teknik triangulasi (Lincoln \& Guba 1984; Moleong 2009).

\section{Hasil dan Pembahasan}

\section{Promosi Wisata Budaya di Kabupaten Banyumas}

Promosi wisata budaya di Kabupaten Banyumas belum benar-benar dilaksanakan dengan baik karena promosi tersebut masih bersifat bisnis dan umum, belum ada program khusus tentang promosi wisata budaya yang masuk dalam peraturan daerah. Promosi wisata yang ada di Kabupaten Banyumas selama ini didasarkan pada Perda No.9 Tahun 1993 Tentang Promosi Wisata Daerah. Dalam Perda (1f) disebutkan bahwa "promosi pariwisata daerah adalah upaya dan kegiatan secara sistematis yang dilaksanakan oleh Daerah (Kabupaten Dati II Banyumas) guna merangsang masyarakat agar menggunakan waktu luangnya untuk melakukan perjalanan wisata di dan ke daerahnya". Teknik promosi meliputi $(4,5,6,7): 1)$ pemasangan iklan (media cetak, elektronik dan ruang terbuka); 2) pengadaan sarana pendukung penjualan (folder, rekaman suara bergambar, peragaan, dII); 3) hubungan masyarakat (widyawisata pengenalan, keikutsertaan dalam kegiatan wisata di dalam dan di luar negeri, humas dengan stakeholders, pementasan festival seni budaya dll, pelayanan informasi kepariwisataan). Sementara itu, penyelenggaraan promosi wisata merupakan wewenang dan tanggung jawab Dinas Pariwisata atas nama Bupati (8). Dinas dapat menyertakan pihak ketiga dalam promosi wisata. Penyelenggaraan promosi ke luar negeri dilakukan dibawah koordinasi Dirjen Pariwisata.

Selama ini, banyak daerah yang mempromosikan budayanya ke luar negeri. Kontingen budaya Banyumas pernah sekali melawat ke Madrid (Spanyol), tetapi itu pun dibiayai oleh Depparbud, Jakarta. Dari Disparbud Banyumas sendiri, tidak pernah mempromosikan budaya Banyumas sampai ke luar negeri. Selama ini Disparbud Banyumas lebih berorientasi pada kegiatan promosi yang bernuansa proyek, yang secara instant bisa menghasilkan uang bagi aparat, misalnya Prosesi Hari Ulang Tahun Kabupaten Banyumas yang dilakukan setiap tahun. Prosesi HUT Kabupaten Banyumas (yang dimulai dari Kotatif sampai alun-alun) tidak tumbuh dalam masyarakat, tetapi sengaja diadakan oleh pemerintah. Ironisnya, tidak ada turis yang muncul dan masyarakat Banyumas sendiri jarang yang berminat datang untuk melihat/ menonton prosesi tersebut. Beda dengan tradisi Jaru Rojab di Kalisalak yang acaranya tidak dikemas dan dihadiri oleh pemerintah, tetapi justru ramai dikunjungi oleh masyarakat. Jelas terlihat di sini bahwa wisata budaya lebih dihargai pada hal-hal yang besifat ritual keagamaan/ kepercayaan. Dalam hal ini, identitas lokal sebagai refleksi nilainilai budaya daerah lebih dipahami sebagai bagian dari hal-hal yang lebih dipengaruhi oleh nilai-nilai keagamaan/ kepercayaan, tidak lagi pada nilai budaya Banyumas itu sendiri. 


\section{Pengembangan Identitas Lokal}

Identitas lokal orang Banyumas adalah Cablaka. Cablaka bermakna apa adanya, apa mestinya; identik atau selaras dengan apa yang disebut transparansi. Bagi orang Banyumasseperti halnya orang Jawa, pada umumnya-nama mempunyai makna. Misalnya, ada nama Senin karena lahirnya hari Senin. Daldiri berarti medal (keluar) sendiri, karena pada waktu itu belum ada bidan, sehingga mbabar (melahirkan) sendiri. Nama Slamet dimaksudkan supaya selamat. Sementara Bawor yang menjadi ikon Banyumas selama ini bermakna tiba awor, yang artinya mudah adaptasi (mudah menyesuaikan dengan perubahan, awor-umor). Bawor juga berarti blakasuta (apa adanya, terbuka, transparan), antep (seperti nada bicara yang mantap), wanteg (tidak mudah terpolusi dengan bahasa apapun), omber (mampu menirukan bahasa-bahasa yang lain), rageg atau reang (kalau berbicara berisik). Dalam dunia pewayangan, tokoh Bawor dikesankan bersifat cablaka, merakyat (orang yang bisa berkomunikasi ke atas maupun ke bawah) dan tidak tinggi diri. Wayang Bawor hanya ada dalam Wayang Banyumasan. Figur Bawor lain dengan Bagong.

Nilai cablaka tercermin dalam wisata budaya Banyumas. Misalnya, nilai cablaka dalam begalan dan kesenian Banyumas lainnya tercermin dalam iramanya yang mantap. Namun demikian, nilai-nilai budaya Banyumas belum tercermin seluruhnya dalam wisata budaya, sehingga para wisatawan belum dapat membedakan budaya Banyumas dengan budaya Jawa pada umumnya. Hal ini terjadi karena potensi wisata budaya Banyumas belum benarbenar digali dan dikembangkan. Penggalian potensi wisata budaya yang dikembangkan dan menghasilkan PAD bisa menunjang kehidupan masyarakat setempat agar bisa lebih baik dan sejahtera.

Budaya Banyumas-khususnya kesenian dan tradisinya-bisa dijual untuk memperoleh PAD seperti di Bali, asalkan ada perluasan informasi mengenai budaya Banyumas yang keluar melalui berbagai cara. Namun saat ini, penghargaan terhadap nilai seni dan budaya di Banyumas saja masih rendah. Oleh karena itu, perlu adanya komitmen para pemimpin dan stakeholders pariwisata untuk mengembangkan budaya Banyumas itu sendiri. Dalam pertunjukan kuda lumping, misalnya, satu paket Ebeg hanya dibayar murah. Padahal pelakunya berjumlah 30 orang, belum sound system dan lain-lain. Satu orang kira-kira hanya mendapat beberapa ribu saja untuk satu hari pertunjukan. Selain itu, perhatian terhadap kualitas kesenian masih rendah. Misalnya, pertunjukan Ebeg sampai sekarang masih memakai karung goni sebagai ornamennya. Hal ini berbeda dengan apa yang terjadi di Bali, di mana wisata budaya telah menyatu dengan kehidupan sehari-hari masyarakat setempat. Selain itu, hukum adat yang berlaku dan sudah terlembaga pun bisa mendukung keberadaan nilai-nilai lokal yang digali dalam pengembangan wisata budaya di Bali. Sedangkan hukum adat di Banyumas belum ada yang terlembaga sebagaimana di Bali, yang ada hanyalah kebiasaan yang berlaku dalam masyarakat.

\section{Kearifan Lokal Dalam Pariwisata}

Dalam kehidupan birokrasi pemerintahan di Kabupaten Banyumas, identitas lokal-cablakatidak jelas tercermin. Menurut informan, itu tergantung pada kepribadian personal dan sejauh mana pengaruh lingkungan terhadap birokrasi dan kepribadian aktor-aktornya. Dalam interaksi kehidupan sosial masyarakat Banyumas, identitas lokal tersebut masih ada/ bisa ditemukan di beberapa tempat. Di beberapa desa, misalnya, masih ada tradisi yang disebut pinggelan. Tradisi ini tercermin dalam sebuah hajatan. Bila ada hajatan, maka yang 
mengundang hajatan meminta jenis barang yang mau disumbangkan berikut jumlahnya kepada yang diundang secara terus terang ("ngarani"). Nanti pada saat yang diundang mempunyai hajatan, dibalas dengan sumbangan yang sama dan serupa dengan yang pernah disumbangkannya terdahulu. Tapi ada pula yang mengundang hajatan tetapi tidak ngarani hanya meminta secara terus terang yang bersangkutan memerlukan bantuan. Dalam kehidupan birokrasi dan masyarakat, budaya terus terang itu sebenarnya ada tetapi bentuk perwujudannya diperhalus. Misalnya, pada saat pemilihan kepala desa (pilkades), permohonan kepada voters dinyatakan melalui beberapa orang dekat

Budaya Banyumas merupakan subbudaya Jawa. Oleh karena itu, budaya Banyumas masih berada dalam lingkup budaya Jawa pada umumnya. Dalam berinteraksi dengan masyarakat, misalnya, kaum priyayi Banyumas (yang kebanyakan mengisi birokrasi pemerintahan) masih mengenal nilai feodalisme yang dipertahankan oleh Pemerintah Kolonial. Sementara masyarakat pun masih berorientasi pada priyayi/ pegawai negeri. Misalnya, ada kata-kata: anakku sing sugih lan singgih (kehormatan karena jabatan); atau kowe nganah dadi pegawai negeri ora ketang gajieh sekethip tapi kan nduwe setrip (jadi pegawai negeri saja, meskipun gajinya sedikit tapi kan punya pangkat). Kehidupan birokrasi di Kabupaten Banyumas masih berprinsip "ngono yo ngono ning ojo ngono".

Ketidakterusterangan tercermin dalam proses pembuatan kebijakan pengembangan pariwisata di Kabupaten Banyumas. Anggaran untuk pengembangan pariwisata dipandang tidak transparan karena tidak mencantumkan indikator-indikator yang jelas dalam hasil-hasil kegiatan yang telah dilakukan pemerintah (lihat dokumen anggaran). Berkenaan dengan soal anggaran, salah satu narasumber mengungkapkan bahwa Dinas Pemuda dan Olahraga Kebudayaan dan Pariwisata (Dinporabudpar) Kabupaten Banyumas selalu ditekan oleh Dewan Perwakilan Rakyat Daerah (DPRD) Kabupaten Banyumas. Ibarat mobil, gasnya diinjak tapi koplingnya juga diinjak, jadi hanya menimbulkan suara mbengung. Di satu pihak, Komisi A dari DPRD Kabupaten Banyumas banyak melakukan pemotongan anggaran yang telah dibuat oleh Dinporabudpar. Namun di lain pihak, Komisi D dari DPRD Kabupaten Banyumas meminta Dinporabudpar untuk menaikkan targetnya dalam upaya pengembangan pariwisata di Kabupaten Banyumas. Padahal di lingkungan birokrasi (termasuk bagian promosi wisata), tidak ada mekanisme reward and punishment (penghargaan dan sanksi). Jika target terpenuhi (padahal target naik setiap tahunnya), tidak ada reward. Namun jika target tidal terpenuhi, ada punishment. Selain itu, selama ini tidak pernah ada evaluasi kebijakan pengembangan pariwisata yang melibatkan stakeholders baik di dalam maupun di luar pemerintah, seperti Perhimpunan Hotel dan Restoran Indonesia (PHRI), Biro Perjalanan Wisata (BPW), Kelompok Sadar Wisata (Pokdarwis), dan masyarakat setempat.

Fokus pemerintah dalam pengembangan pariwisata-di Baturraden, misalnya, yang menjadi objek wisata unggulan di Kabupaten Banyumas-adalah aspek bisnis. Misalnya, pembinaan masyarakat seperti sopir angkutan umum, pemilik warung, dan sebagainya). Pembinaan terhadap pengusaha warung, misalnya, difokuskan pada permintaan untuk mencantumkan harga-harga secara jelas kepada pelanggan. Tarif menu harus dipasang di setiap warung. Hal ini dimaksudkan agar wisatawan tidak "lari" dari Baturraden. Di sini, terlihat bahwa penekanan pada aspek bisnis hanya berimplikasi pada kepentingan jangka pendek. Sementara kepentingan jangka panjang hanya bisa dipenuhi dengan memberi fokus 
pengembangan pariwisata pada pengembangan nilai-nilai budaya. Dalam hal ini, pengembangan identitas lokal menjadi signifikan dalam pengembangan pariwisata.

Tidak adanya transparansi anggaran untuk pengembangan wisata di Kabupaten Banyumas terjadi karena tidak adanya pemahaman yang menyeluruh tentang prioritas dan sustainabilitas pengembangan wisata-khususnya budaya-yang berdasarkan identitas lokal. Ketidaktahuan akan signifikansi identitas lokal menyebabkan kebijakan lebih dibuat dan diberlakukan secara pragmatis (market demand). Jadi semakin jelas bahwa kebijakan pengembangan pariwisata lebih dibuat dan diberlakukan untuk kepentingan jangka pendek. Pembinaan yang dilakukan pemerintah terhadap masyarakat (di sekitar objek wisata) sebenarnya sudah jelas. Ada pembinaan untuk memproduksi barang-barang dan memberi peluang pemasarannya-menghubungi keyperson/s di Dinas Perindustrian dan Perdagangan, misalnya-tetapi hasilnya masih kurang efektif. Tampaknya masyarakat hanya menyadari nilai bisnisnya, bukan menyadari nilai budayanya. (Contoh: penjualan bunga-bunga tiruan/ artifisial, baik dalam ukuran aslinya maupun dalam bentuk miniatur. Dalam hal ini, pihak Disparbud menghimbau para wisatawan dengan memberikan peringatan tertulis untuk tidak membeli bunga-bunga tiruan tersebut. Selain untuk melindungi para wisatawan dari tindakan penipuan, upaya ini juga bertujuan untuk melindungi para pedagang yang menjual bunga-bunga asli supaya tidak merugi.)

Di objek wisata alam, budaya - dalam hal ini kesenian dan tradisi - hanya bersifat komplementer karena hanya berfungsi sebagai hiburan saja/ sekedar tontonan. Di satu sisi, misalnya, pertunjukan lengger dan ebeg jarang digelar. Namun di sisi lain, terutama hari Minggu, pertunjukan konser dangdut sering digelar untuk menyedot pengunjung di objek wisata tersebut. Jadi sepertinya tidak ada nuansa Banyumas di Baturraden/ objek wisata alam lainnya. Untuk pertunjukan musik, misalnya, hotel-hotel di Kawasan Wisata Baturraden/ Banyumas menyuguhkan lagu-lagu asing untuk menyambut wisatawan, bukan memperdengarkan tembang-tembang Banyumasan. Bahkan pertunjukan tari yang digelar bukan tari-tarian Banyumasan, melainkan tarian asing seperti striptease dan sebagainya. Selain itu, fasilitas khusus/ istimewa yang diberikan oleh penginapan-penginapan yang ada di kawasan wisata tersebut lebih bernuansa modern daripada tradisional. Hotel Queen Garden, misalnya, menyediakan fasilitas diskotik yang diberi nama Lengger Diskotik. Selama ini nampaknya upaya promosi (atau tindakan pemerintah seperti sosialisasi) belum sampai ke sana.

\section{Kesimpulan}

Cablaka sebagai refleksi dari nilai budaya Banyumas belum menyatu dengan gaya hidup wisata pelaku/ pengguna kebudayaan Banyumas. Ini berarti nilai budaya cablaka pun belum sepenuhnya menjadi identitas lokal Banyumas yang menjiwai kehidupan masyarakatnya di berbagai sektor kegiatan, termasuk sektor pariwisata. Padahal identitas lokal dalam pengembangan pariwisata - khususnya promosi wisata budaya - bukan hanya soal seperti apa kesenian dan tradisinya, tapi juga bagaimana nilai-nilai lokal masuk dalam program pengembangan pariwisata itu sendiri.

Promosi wisata budaya yang dilakukan selama ini lebih bertumpu kepada promosi hasil-hasil kebudayaan, bukan nilai-nilai budaya yang mendasari kegiatan budaya/ kebudayaan Banyumas itu sendiri. Padahal yang penting dan pokok dalam pengembangan pariwisata - 
khususnya promosi wisata budaya- di Kabupaten Banyumas adalah bukan hanya tentang bagaimana institusi-institusi pengembangnya bisa menyuguhkan kesenian dan tradisi Banyumas, tetapi juga tentang bagaimana kesenian dan tradisi Banyumas itu sendiri bisa diterima oleh para wisatawan. Dalam hal ini, bagaimana identitas lokal sebagai refleksi dari kebudayaan Banyumas itu sendiri mampu melawan arus kuat globalisasi. Tidak adanya upaya untuk mengembangkan identitas lokal terjadi karena identitas lokal itu sendiri belum dipahami secara benar dan serius oleh institusi-institusi pengembang yang berwenang. Sementara pembinaan yang dilakukan pemerintah terhadap masyarakat (di sekitar objek wisata) lebih difokuskan pada hal-hal yang bersifat material, bukan pada nilai-nilai/ hal-hal yang bersifat substansial. Hal inilah yang menyebabkan pengembangan pariwisata khususnya wisata budaya- di Kabupaten Banyumas belum dapat mencapai hasil yang baik dan bermanfaat bagi pelaku dan pengguna kebudayaan Banyumas itu sendiri.

Jadi jelas bahwa pengembangan identitas lokal yang mencerminkan kearifan lokal suatu daerah adalah penting dan menjadi suatu kebutuhan yang harus dipenuhi dalam proses pengembangan pariwisata di Kabupaten Banyumas. Pengembangan pariwisata di Kabupaten Banyumas melalui promosi wisata budayanya menjadi hak dan tanggung jawab semua pihak yang terlibat dalam proses tersebut. Dengan kata lain, promosi wisata budaya harus bersifat demokratis. Dalam hal ini, promosi wisata budaya harus dilakukan 'oleh', 'dari', dan 'untuk' keempat unsur utama dalam pengembangan pariwisata di suatu daerah, yaitu: wisatawan, pengusaha/ wiraswastawan, pemerintah daerah dan masyarakat setempat.

\section{Daftar Pustaka}

Anonymous, 2000. Analisa SWOT (Strength, Weakness, Opportunity, Threats) Pengembangan Pariwisata Kabupaten Banyumas. Purwokerto: Diparta Kabupaten Banyumas.

BPS, 2004. Kabupaten Banyumas Dalam Angka 2004. Purwokerto: Badan Pusat Statistik Kabupaten Banyumas.

Eagleton, Terry, 2000. The Idea of Culture. Oxford: Blackwell Publishers.

Gertler, Len, 1992. "Linkage Between Past, Present and Future". Dalam Wiendu Nuryanti (chief-ed.), Universal Tourism Enriching or Degrading Culture? (Proceedings on the International Conference on Cultural Tourism). Yogyakarta: Gadjah Mada University Press.

Hill, Hall. "The Economy", dalam Hill, Hall (ed), 1994, Indonesia`s New Order: The Dynamics of Socio-Economics Transformation. Australia: Allen \& Unwin Pty Ltd.

Huttington, Samuel P., 2000. "Cultures Count". Dalam Lawrence E. Harrison \& Samuel P. Huttington (eds.), Culture Matters: How Values Shape Human Progress. New York: Basic Books.

Lincoln, Yvonna dan Egon G. Guba, 1984. Naturalistic Inquiry. Beverly Hills, London: Sage Publications.

McIntosh, Robert W., Charles R. Goeldner \& J.R. Brent Richie, 1995. Tourism: Principles, Practices, Philosophies; Seventh Edition. New York: John Wiley \& Sons, Inc.

Miles, B. Matthew dan A. Michael Huberman (terjemahan), 1994. Analisis Data Kualitatif. Jakarta: UI Press.

Moleong, Lexy J., 1990. Metodologi Penelitian Kualitatif. Bandung: PT. Remaja Rosdakarya 
Spradley, James P. \& Michael A. Rynkiewich, eds., 1975. The Nacirema. Boston, Massachussetts: Little, Brown and Company.

Suparlan, Parsudi, (tanpa tahun). "Kebudayaan dan Pembangunan". Dalam Kajian-Kajian Antropologi Masa Kini: Suatu Bunga Rampai; Media IKA. Jakarta IKA UI.

Susanto, Hery, dkk, 2003. Otonomi Daerah dan Kompetensi Lokal: Pikiran Serta Konsepsi Syaukani HR. Jakarta: Millenium Publisher.

Wallerstein, Immanuel, 1991. "The Construction of Peoplehood: Racism, Nationalism, Ethnicity". Dalam Etienne Balibar \& Immanuel Wallerstein (eds.), Race, Nation, Class: Ambiguous Identities; English Language Edition. London: Verso. 